izing agents for the circadian rhythms of other animals - apparently are only subsidiary in humans to the stronger effects of various sorts of social synchronization.

Wever himself has supervised all the massive programme of research described here, and the interpretations of the data are, of course, his own. Some of those interpretations are inevitably less convincing than others, and each reader will no doubt find certain issues about which he has reservations. It strikes me, for example, as over-interpretation, when the phase relationship between the bodytemperature rhythm and the wake-sleep cycle is taken not just as a hint, but as proof that a subject's rhythm was accidentally synchronized by some unintended environmental cycle (p.38). I also wonder what to think about the implications of electromagnetic fields for the rhythms: small differences in mean period, correlated with shielding from natural electromagnetic fields, were statistically significant during the first 5 years of experimentation $(n=84)$; but $I$ find it distressing to see that the effect was not reproduced during the subsequent 8 years of studies (p.96; $n=58$ ). An imposed $10-\mathrm{Hz}$ squarewave electric field was associated with a shorter circadian period for 12 of 17 subjects tested (the other 5 excluded because of "internal desynchronization"'); but in subsequent experiments, a $10-\mathrm{Hz}$ sinusoidal field led to equivocal results (p.114). This difference can in principle be attributed to higher harmonics in the square-wave signal - or does it instead reflect on the reproducibility of the initial finding?

But these and similar questions are minor matters. Regardless of details in the interpretation, this monograph offers a wealth of data; it is an irreplaceable source book for those interested in the experimental study of human circadian clocks.

J.T. Enright is Professor of Behavioral Physiology at the Scripps Institution of Oceanography, La Jolla, California.

\section{Igneous petrology fifty years on}

\section{R. N. Thompson}

The Evolution of the Igneous Rocks. Fiftieth Anniversary Perspectives. Edited by H.S. Yoder Jr. Pp.588. (Princeton University Press: Guildford, UK, 1979.) Hardback $£ 19.30$; paperback $£ 8.40$.

IN 1928 N. L. Bowen wrote his masterpiece The Evolution of the Igneous Rocks. This book caused a revolution in the philosophy and approach of igneous petrology by demonstrating that many aspects of the behaviour of magmas could be explained adequately by straightforward application of chemical principles, without the addition of the pinch or two of geological magic dust so frequently used by other theoreticians of Bowen's time. The 18 eminent petrologists who have contributed to the fiftieth anniversary volume are all the inheritors of Bowen's approach to magma chemistry. Each was asked to take a chapter of the original book and describe what has happened in that part of the subject during the following half century. As might be expected, there are great differences in the ways in which the various authors have approached their task. Some of them alternate extensive quotations from Bowen, or paraphrases of his ideas, with balanced summaries of the present state of knowledge on each theme. In contrast, a few of the contributors have been unable to resist the temptation to use their chapters almost solely as vehicles for summarizing their own work and reiterating their own views; in one article there is no mention at all of either Bowen or his book. articles far outweigh the few others. The chapters that I found particularly interesting were on silicate liquid immiscibility (Roedder), crystal accumulation and sorting (Irving), siliceous potassic glassy rocks (Stewart), volatile constituents (Burnham) and petrogenesis (Wyllie). There are also many sections of valuable data and discussions in other chapters and I anticipate that this book is one which almost every working igneous petrologist or geochemist will wish to buy. On the other hand, it is probably of only limited use to the wider readership of students. The reason for this lies in the terms of reference of the volume. Rigorous adherence by the contributors to the themes in igneous petrology which Bowen chose in 1928 has inevitably led to omission, or virtual omission, from the 1979 book of any subjects which were neglected or completely unrecognized 50 years ago. This policy leads to a curious overall impression in the book, because many aspects of current igneous petrology are discussed in detail, whilst other important themes, such as crystallization kinetics, and trace-element and isotope geochemistry, are almost completely omitted. The irony is that, if Bowen had rewritten his own book in 1979 , these are exactly the sorts of forward-looking applications of chemical principles to igneous petrology that he would have emphasized.

$R$. N. Thompson is Lecturer in Geology at the Imperial College of Science and Technology, University of London, UK.
Taken as a whole, the many excellent

\section{Selective electrodes}

\section{J.A.W. Dalziel}

Working with Ion-Selective Electrodes. By

K. Cammann. Pp.225. (Springer: Berlin, Heidelberg and New York, 1979.) DM 76, $\$ 41.80$.

THIS monograph, a worthy successor to others that have appeared, is a translation from a second German edition. It reviews 447 publications up to 1977 . The author, after experience in the applications department of an instrument manufacturer, claims an understanding of the problems that face the users of ion-selective electrodes. He considers that their difficulties arise mainly from lack of knowledge and remedies this in two ways - first, with a theoretical treatment to serve as reference in understanding the action of electrodes in potentiometry generally, and then by offering practical advice on their construction, mode of operation and a survey of their present range of applications.

Particular emphasis is given to consideration of pitfalls in the reproducible measurement of electrode potentials, with advice on reference electrodes, buffers and liquid junction potentials directed towards stable e.m.f. measurements of high impedance cells. The different categories of ion-selective electrodes (solid-state glass, homogeneous and heterogeneous membranes, supported ion exchanger and neutral carrier membranes, and electroactive coatings, gas-diffusion and bio sensors, but without the glass $\mathrm{pH}$ electrode which is intentionally omitted) are all described in turn with full practical details, including methods of construction.

The second half of the book has sections on techniques and applications. Besides calibration and the direct measurement of activity (concentration) under static conditions, much space is devoted to titration procedures with indicator electrodes, using the Gran extrapolation and other methods which allow for the slow response of some electrodes near the end point. Whether such methods would be chosen for routine situations is questionable. The short section on continuous measurements in industry and environmental research should be more interesting, but in fact the progress reported is rather disappointing when one remembers that it is over 15 years since 'new' ionselective electrodes were made. For the future, the important step will be to discover better ways of interfacing the electrolytic species in sample solutions so that they react directly and selectively with electronic charge carriers within semiconducting electrodes.

J.A.W. Dalziel is Reader in Analytical and Inorganic Chemistry at Chelsea College, University of London, UK. 